\title{
Divergence rates of subviral pathogens of angiosperms abruptly decreased at the Cretaceous-Paleogene boundary
}

\author{
Piotr Bajdek ${ }^{1, *}$
}

\author{
I Al. N.M.P. 20/20A, 42-200 Czestochowa, Poland \\ Corresponding author: Piotr Bajdek (piotr.bajdek@gmail.com)
}

Academic editor: Frans Jorissen | Received 11 January 2019 | Accepted 19 April 2019 | Published 10 May 2019

Citation: Bajdek P (2019) Divergence rates of subviral pathogens of angiosperms abruptly decreased at the CretaceousPaleogene boundary. Rethinking Ecology 4: 89-101. https://doi.org/10.3897/rethinkingecology.4.33014

\begin{abstract}
Biogeographic distribution of infected plants and the continental drift theory allow a tentative time calibration of the phylogenetic tree of Pospiviroidae. Hypothetically, viroids evolved in the late Early Cretaceous shortly after the appearance of angiosperms, which constitute their only known hosts. No decline in the estimated divergence rates of Pospiviroidae is observed during the Late Cretaceous but it appears that they abruptly decreased at the Cretaceous-Paleogene boundary. However, an adaptive radiation of Pospiviroidae which occurred in the late Paleocene may reflect a recovery from the Cretaceous-Paleogene $(\mathrm{K}-\mathrm{Pg})$ mass extinction. It seems that the evolutionary history of viroids has been in part shaped by radiation and extinction events of angiosperms. Herein, for the first time I show the probable impact of a mass extinction event on the divergence rates of subviral pathogens, which are the simplest known "lifeforms".
\end{abstract}

\section{Keywords}

mass extinctions, viroids, paleovirology

\section{Introduction}

Mass extinction events play a fundamental role in shaping the biosphere (Raup and Sepkoski 1982; Novacek 1999; McElwain and Punyasena 2007; Chin et al. 2013; Niedźwiedzki et al. 2016). Wang et al. (2011) suggested that mass extinctions might have also impacted on the evolutionary history of viruses. This is a reasonable concept since

\footnotetext{
* Independent researcher
} 
the evolution of viruses should have been in part shaped by the history of their hosts (see Thézé et al. 2011). However, data demonstrating the impact of global mass extinctions on the diversity or divergence rates of viral or subviral pathogens have never been discussed.

Viroids are small (246-399 nucleotides), unencapsidated, single-stranded, circular RNAs, which are known to infect solely angiosperm plants (Diener 1971, 2003; GóraSochacka 2004; Flores et al. 2005). Viroids differ from viruses by a much smaller genome size and, in contrast to viruses, do not code for any protein. Viroids are classified as subviral particles and, alongside small linear and circular satellite RNAs, constitute the smallest pathogens and "lifeforms" known (Elena et al. 1991; Flores et al. 2014; AbouHaidar et al. 2016). Viroids appear to be evolutionarily related to satellite RNAs, including the human Hepatitis delta virus (Elena et al. 1991, 2001). However, in contrast to satellite RNAs, viroids complete their infectious cycle without resorting to a helper virus (Daròs et al. 2006). Viroids are divided into two families, Pospiviroidae and Avsunviroidae, which replicate either in the nuclei or in the chloroplasts, respectively (Tsagris et al. 2008; Flores et al. 2012; Rao and Kalantidis 2015).

In this paper, I present a time-calibrated phylogenetic tree of members of the family Pospiviroidae. I also estimate the divergence rates of Pospiviroidae throughout the Cretaceous and the Paleogene. The hypothetical impact of the Cretaceous-Paleogene $(\mathrm{K}-\mathrm{Pg})$ extinction event on the divergence rates of this viroid family is discussed.

\section{Material and methods}

Evolutionary analyses involved 34 nucleotide sequences of viroids belonging to the families Pospiviroidae (30 sequences) and Avsunviroidae (4 sequences) (Table 1), which were downloaded from the National Center for Biotechnology Information, U.S. National Library of Medicine. Sequence alignment was performed by the MUSCLE algorithm. The analyses were conducted in MEGA X (Kumar et al. 2018) under Debian/GNU Linux 9.6. “Stretch”.

\section{Phylogeny}

The phylogenetic tree of viroids was constructed by using the Maximum Likelihood method and General Time Reversible model (Nei and Kumar 2000). The tree with the highest $\log$ likelihood (-11928.92) is shown in Fig. 1. The percentage of trees in which the associated taxa clustered together is shown next to the branches. Initial tree for the heuristic search was obtained automatically by applying Neighbor-Join and BioNJ algorithms to a matrix of pairwise distances estimated using the Maximum Composite Likelihood (MCL) approach, and then selecting the topology with superior log likelihood value. The tree is drawn to scale, with branch lengths measured in the number of substitutions per site (Fig. 1). 
Table I. Nucleotide sequences involved in this study.

\begin{tabular}{|c|c|c|c|c|}
\hline $\begin{array}{c}\text { Accession } \\
\text { number }\end{array}$ & $\begin{array}{l}\text { Sequence } \\
\text { length }\end{array}$ & Viroid & Genus & Family \\
\hline NC 000885.1 & 360 & Tomato chlorotic dwarf viroid & Pospiviroid & Pospiviroidae \\
\hline NC 001340.1 & 329 & Apple scar skin viroid & Apscaviroid & Pospiviroidae \\
\hline NC 001351.1 & 302 & Hop stunt viroid & Hostuviroid & Pospiviroidae \\
\hline NC 001410.1 & 247 & Avocado sunblotch viroid & Avsunviroid & Avsunviroidae \\
\hline NC 001462.1 & 246 & Coconut cadang-cadang viroid & Cocadviroid & Pospiviroidae \\
\hline NC 001464.1 & 371 & Citrus exocortis viroid & Pospiviroid & Pospiviroidae \\
\hline NC 001471.1 & 254 & Coconut tinangaja viroid & Cocadviroid & Pospiviroidae \\
\hline NC 001553.1 & 360 & Tomato apical stunt viroid & Pospiviroid & Pospiviroidae \\
\hline NC 001558.1 & 360 & Tomato planta macho viroid & Pospiviroid & Pospiviroidae \\
\hline NC 001651.1 & 315 & Citrus bent leaf viroid & Apscaviroid & Pospiviroidae \\
\hline NC 001830.1 & 315 & Pear blister canker viroid & Apscaviroid & Pospiviroidae \\
\hline NC 001920.1 & 366 & Grapevine yellow speckle viroid 1 & Apscaviroid & Pospiviroidae \\
\hline NC 002015.1 & 356 & Chrysanthemum stunt viroid & Pospiviroid & Pospiviroidae \\
\hline NC 002030.1 & 359 & Potato spindle tuber viroid & Pospiviroid & Pospiviroidae \\
\hline NC 003264.1 & 292 & Citrus dwarfing viroid & Apscaviroid & Pospiviroidae \\
\hline NC 003463.1 & 306 & Apple dimple fruit viroid & Apscaviroid & Pospiviroidae \\
\hline NC 003538.1 & 370 & Columnea latent viroid & Pospiviroid & Pospiviroidae \\
\hline NC 003539.1 & 284 & Citrus viroid IV virus & Cocadviroid & Pospiviroidae \\
\hline NC 003540.1 & 399 & Chrysanthemum chlorotic mottle viroid & Pelamoviroid & Avsunviroidae \\
\hline NC 003553.1 & 369 & Australian grapevine viroid & Apscaviroid & Pospiviroidae \\
\hline NC 003611.1 & 256 & Hop latent viroid & Cocadviroid & Pospiviroidae \\
\hline NC 003613.1 & 370 & Iresine viroid 1 & Pospiviroid & Pospiviroidae \\
\hline NC 003636.1 & 337 & Peach latent mosaic viroid & Pelamoviroid & Avsunviroidae \\
\hline NC 003637.1 & 360 & Mexican papita viroid & Pospiviroid & Pospiviroidae \\
\hline NC 003777.1 & 371 & Apple fruit crinkle viroid & unclassified & Pospiviroidae \\
\hline NC 003882.1 & 295 & Coleus blumei viroid & Coleviroid & Pospiviroidae \\
\hline NC 004359.1 & 330 & Citrus viroid VI & Apscaviroid & Pospiviroidae \\
\hline NC 010165.1 & 294 & Citrus viroid $\mathrm{V}$ & Apscaviroid & Pospiviroidae \\
\hline NC 010308.1 & 396 & Persimmon viroid & unclassified & Pospiviroidae \\
\hline NC 011590.1 & 348 & Pepper chat fruit viroid & Pospiviroid & Pospiviroidae \\
\hline NC 020160.1 & 342 & Dahlia latent viroid & Hostuviroid & Pospiviroidae \\
\hline NC 027432.1 & 351 & Portulaca latent viroid isolate $\mathrm{Vd} 21$ & Pospiviroid & Pospiviroidae \\
\hline NC 028131.1 & 328 & Grapevine latent viroid & unclassified & Pospiviroidae \\
\hline NC 039241.1 & 333 & Eggplant latent viroid & Elaviroid & Avsunviroidae \\
\hline
\end{tabular}

\section{Time calibration}

Members of the family Avsunviroidae were used to root the phylogenetic tree of Pospiviroidae. Divergence times of branches of Pospiviroidae were computed in MEGA X (see Mello 2018) based on five calibration points (A-E) (Fig. 2).

(A) (maximal divergence time: 100 mya) - Nearly 90\% of viroids of this branch infect primarily angiosperms native to South America. Hypothetically, viroids of the branch A diverged after the separation of South America from other continents, which occurred 100 mya (Seton et al. 2012). However, some viroids have crossed this biogeographic barrier or have been recently spread by plant cultivators. 
(B) (maximal divergence time: 100 mya) - Viroids of the branch $\mathrm{B}$ constitute the sister group of the branch A viroids. However, $75 \%$ of viroids of the branch B infect plants native to the Old World and North America. Noteworthy, the Iresine viroid 1 infects traded ornamental plants of a varied provenance including certain South American species but is known only from Europe, North America and Asia (Verhoeven et al. 2017). Viroids of the branch B have hypothetically diverged after the separation of South America from North America and Africa.

(C) (minimal divergence time: 100 mya) - The branch $\mathrm{C}$ encompasses the subbranches A and B. As it contains both typically South American viroids (branch A) and non-South American viroids (branch B), their divergence have likely occurred before the separation of South America from other continents and hence earlier than 100 mya (see Seton et al. 2012).

(D) (maximal divergence time: 100 mya) - This branch includes viroids infecting plants native to Asia and North America. None of these viroids infects South American plants. They would have likely diverged after the separation of South America from other continents.

(E) (maximal divergence time: 100 mya) - This is a big branch of viroids which are unknown to infect South American angiosperms. The branch E viroids would have likely diversified after the separation of South America from other continents.

\section{Divergence Rates}

The time-calibrated phylogenetic tree (Fig. 2) was used to estimate the divergence rates of Pospiviroidae in different epochs of the Cretaceous and the Paleogene periods. Divergence/speciation rate is understood as the number of divergence events divided by epoch duration. Calculations are provided in the Table 2. Duration of given epochs was estimated based on the International Chronostratigraphic Chart v. 2018/08 (Cohen et al. 2013, updated 2018).

\section{Results}

\section{Phylogeny}

Monophyly of the families Pospiviroidae and Avsunviroidae was supported by the initial tree obtained in the analyses, as these families form two separate branches (Fig. 1). However, all attempts to build a bootstrap consensus tree resulted in placing Avsunviroidae as a subgroup within the much larger family Pospviroidae (Fig. 2). Results of the molecular dating suggest that Pospiviroidae appeared $\approx 116.6$ mya (Fig. 2). Depending on the phylogenetic position of Avsunviroidae, this dating either matches or closely approximates also to the divergence time of all the crown-group viroids. It corresponds to the Aptian Age of the Early Cretaceous Epoch (Cohen et al. 2013, updated 2018). 


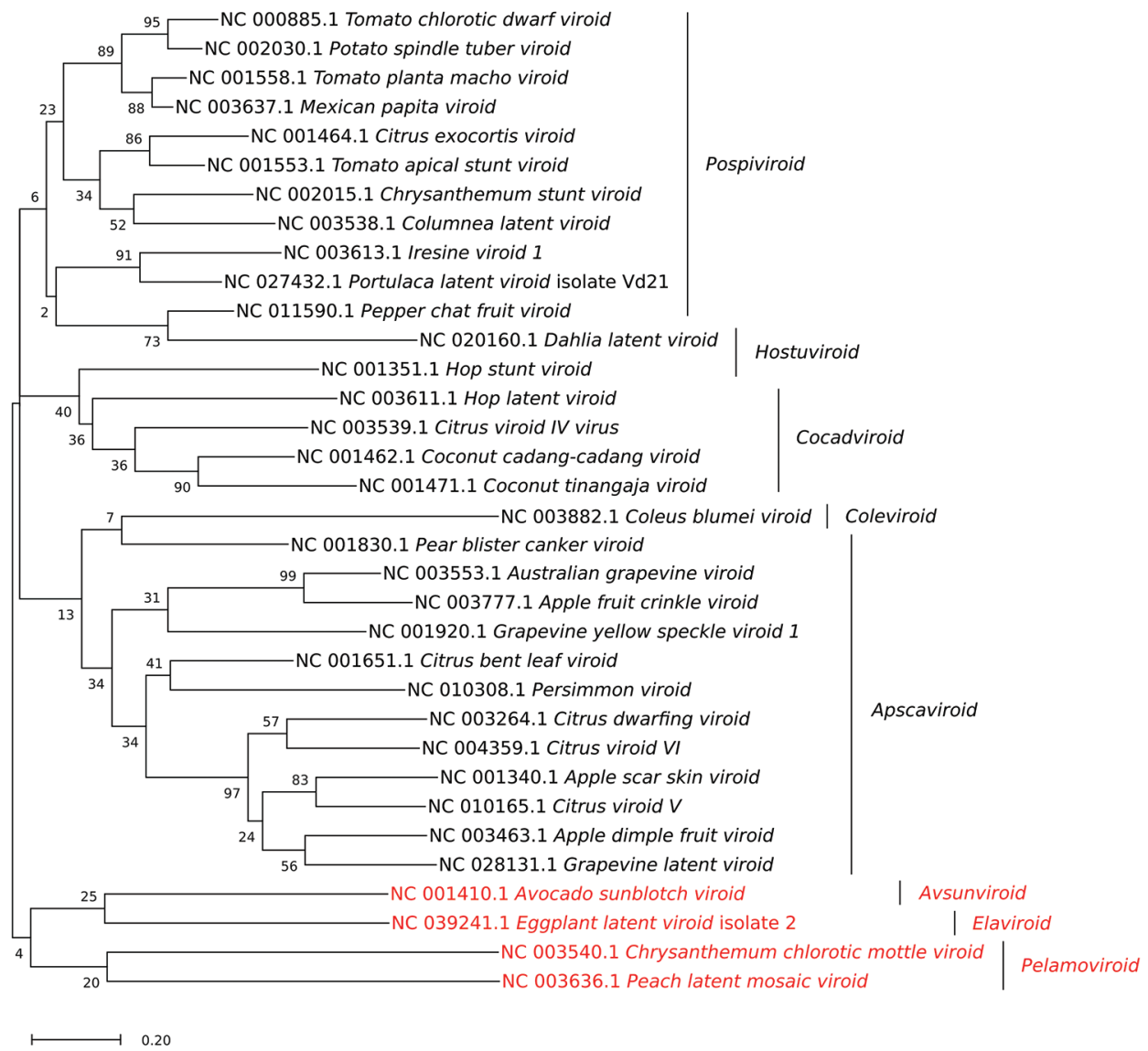

Figure I. Phylogenetic tree of viroids including Pospiviroidae (in black) and Avsunviroidae (in red). Assignment of the Dahlia latent viroid to the genera Pospiviroid or Hostuviroid is problematic (Verhoeven et al. 2013).

The constructed phylogenetic trees (Figs 1,2) are fairly comparable to results obtained by others by the use of distinct algorithms. However, more nucleotide sequences are involved than in earlier studies (Elena et al. 1991, 2001; Owens et al. 2012; Verhoeven et al. 2013; Di Serio et al. 2018).

\section{Divergence Rates}

Divergence rates of Pospiviroidae had been growing since their appearance in the late Early Cretaceous until the end of the Cretaceous Period (Table 2; Fig. 3). No decline in the estimated divergence rates is observed during the latest Cretaceous. Conversely, the Maastrichtian Age (72.1-66 mya) was characterized by the highest divergence rates (0.491) of Pospiviroidae during the Cretaceous Period. 


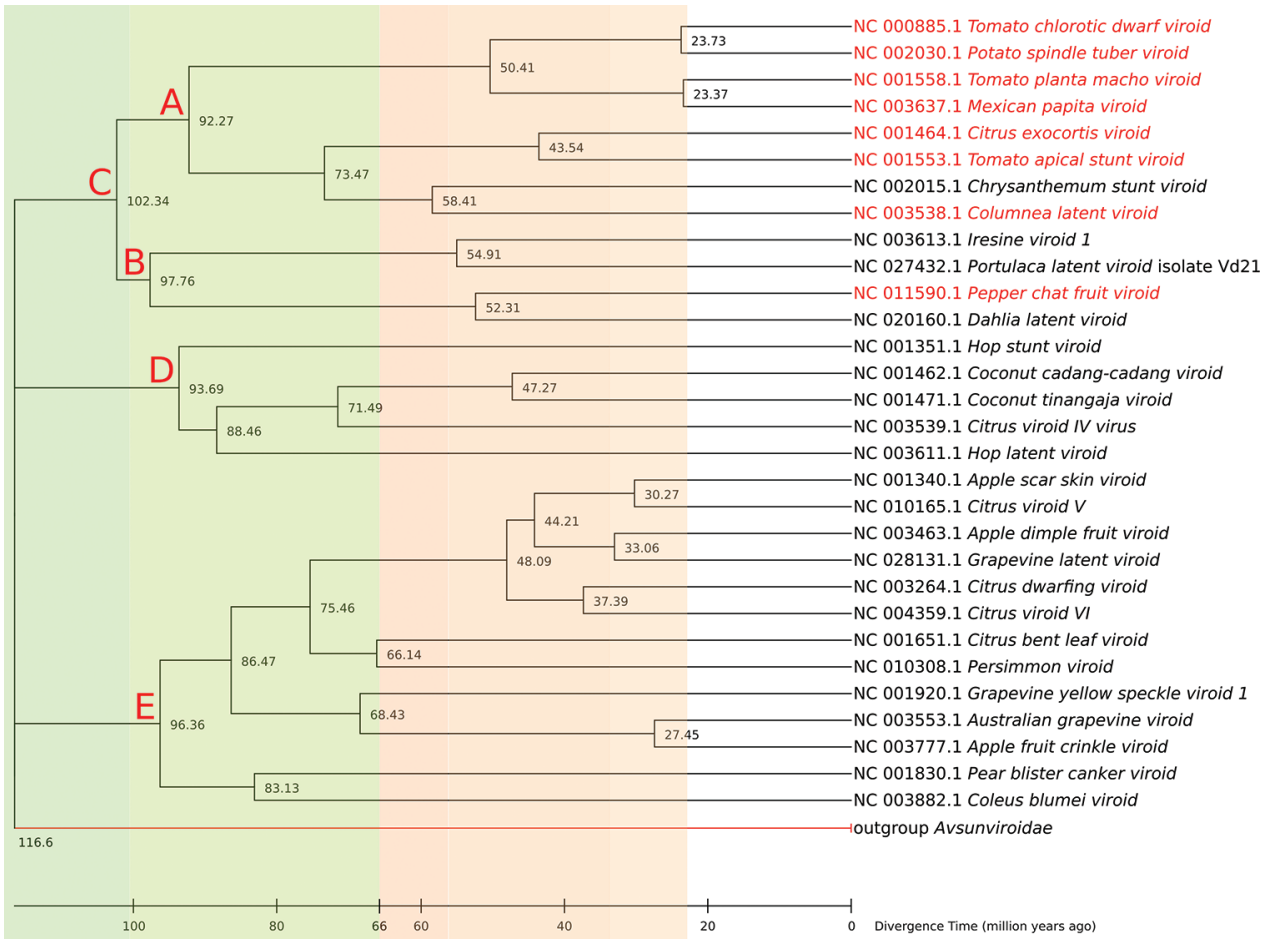

Figure 2. Time-calibrated phylogenetic tree of Pospiviroidae. A-E Calibration points (see Material and Methods). Viroids typically infecting plants native to South America are marked in red.

Table 2. Divergence rates of Pospiviroidae throughout the Cretaceous and the Paleogene.

\begin{tabular}{lccccc}
\hline \multicolumn{1}{c}{ Period } & \multicolumn{2}{c}{ Cretaceous } & \multicolumn{3}{c}{ Paleogene } \\
\hline \multicolumn{1}{c}{ Epoch } & $\begin{array}{c}\text { Early } \\
\text { Cretaceous }\end{array}$ & $\begin{array}{c}\text { Late } \\
\text { Cretaceous }\end{array}$ & Paleocene & Eocene & Oligocene \\
\hline Divergence events & 3 & 12 & 1 & 8 & 5 \\
Epoch duration (million years) & $16.1^{*}$ & 34.5 & 10 & 22.1 & 10.87 \\
$\begin{array}{l}\text { Divergence rates (divergence } \\
\text { events / epoch duration) }\end{array}$ & 0.186 & 0.347 & 0.100 & 0.361 & 0.459 \\
\hline
\end{tabular}

*since the divergence of viroids 116.6 million years ago

Divergence rates of Pospiviroidae abruptly decreased at the Cretaceous-Paleogene boundary. On the constructed phylogenetic tree, no single divergence event is recorded for the Danian and Selandian ages of the early and middle Paleocene Epoch. In other words, there are no recorded divergence events for the first 7.59 million years following the $\mathrm{K}-\mathrm{Pg}$ mass extinction (Fig. 2). However, an adaptive radiation of Pospiviroidae occurred by the late Paleocene and the divergence rates were growing throughout the Eocene and the Oligocene (Table 2; Fig. 3). 


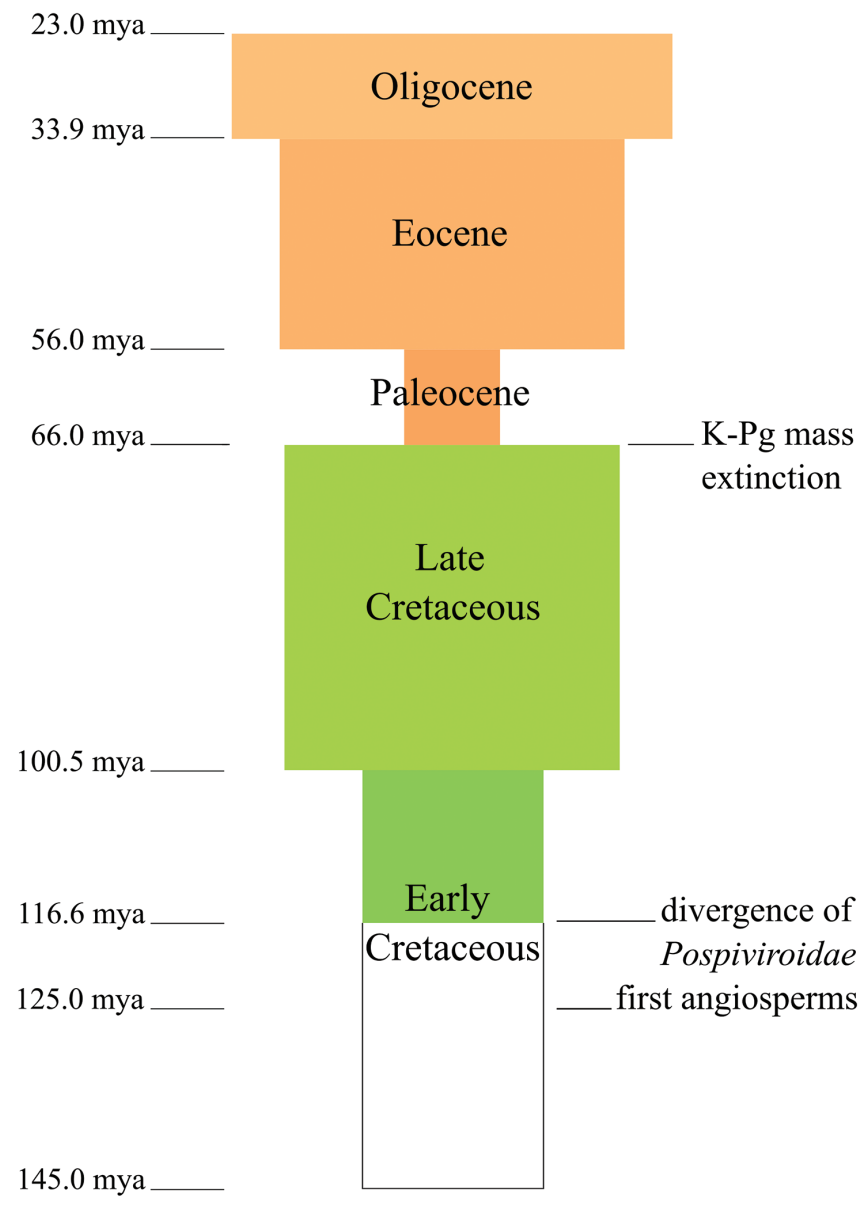

Figure 3. Relative divergence rates of Pospiviroidae symbolized by the column width; drawn based on the Table 2.

\section{Discussion}

Because there is no fossil record of viruses, paleovirology relies on analyses of modern genetic information (Patel et al. 2011; Aswad and Katzourakis 2012; Feschotte and Gilbert 2012; Taylor et al. 2014). The origin of certain virus groups has been dated back to the Mesozoic (Suh et al. 2013, 2014) and even to the Paleozoic (Thézé et al. 2011). It appears that a possible impact of mass extinctions on the evolution of viruses and subviral pathogens might be relevant at least in case of the end-Permian (251.9 mya), end-Triassic (201.3 mya), and the end-Cretaceous (66 mya) events.

Viroids and viroid-like satellite RNAs have been suggested to possibly represent relics of the primordial RNA world (Diener 1989; Chela-Flores 1994; Flores et al. 2014), which 
hypothetically existed before the beginning of cellular life about 4 billion years ago (Gilbert 1986; Cech 2012). This concept is based on the small and circular genome and no proteincoding capacity in all viroids, and also on the presence of hammerhead ribozymes in members of the family Avsunviroidae, which act as catalitic RNAs, as expected for primitive selfreplicating lifeforms of the primordial RNA world (Diener 1989; Chela-Flores 1994; Flores et al. 2014). Since members of the family Avsunviroidae replicate in chloroplasts, their ancestor could hypothetically infect endosymbiotic cyanobacteria (Chela-Flores 1994).

However, members of the family Avsunviroidae are not capable of replication without resorting to a host despite their ribozymatic activity (Rao and Kalantidis 2015). They are solely known to infect angiosperms (an evolutionarily young group) and unknown to replicate in chloroplasts of other eukaryotes. On the other hand, viroids are usually described from cultivated plants, such as fruit trees, vegetables, and ornamental plants, whereas pathogens of most plant groups seem poorly studied. However, the Early Cretaceous origin of viroids inferred from molecular dating in this study and their close association with angiosperm plants do not support the hypothesis of viroids as relics from the primordial RNA world. Angiosperms, which constitute the only known hosts of viroids, evolved over 124.6 mya (Sun et al. 2002), which was soon followed by the appearance of viroids $\approx 116.6$ mya, as inferred from molecular dating (Fig. 3). Possible pre-Cretaceous origin of angiosperm plants is still a subject of debate (Herendeen et al. 2017; Wang 2017; Fu et al. 2018).

The last common ancestor of the closely related Coconut cadang-cadang and Coconut tinangaja viroids infecting coconut palms (Gitau et al. 2009) is dated to $\approx 47.27$ mya based on molecular data analyzed in this study (Fig. 2). Interestingly, this would imply their split shortly after the appearance of coconut palms, which evolved in the early Eocene (Shukla et al. 2012). However, certain viroids are capable of infecting a variety of host taxa (Verhoeven et al. 2017). Rather than to simply mirror the taxonomy of infected angiosperms the phylogenetic tree of viroids has been also shaped by the paleobiogeographic distribution of hosts and the continental drift (Fig. 2).

The estimated divergence rates of Pospiviroidae were particularly low in the Paleocene Epoch (Table 2; Fig. 3), which may be interpreted as a possible effect of the end-Cretaceous extinction. The $\mathrm{K}-\mathrm{Pg}$ mass extinction event caused a disappearance of $\approx 57 \%$ of all plant species in North America (Wilf and Johnson 2004). Decrease in host population size and host isolation would have probably led to a mass extinction of viruses (Wang et al. 2011). Viroids can be transmitted by a direct contact between plants, seeds, pollen, and occasionally by insects when encapsidated by a virus (Syller et al. 1997; Card et al. 2007; Van Bogaert et al. 2014). Studies on insect-feeding damages of angiosperm leaves suggest a disappearance of most specialized plant-insect associations at the K-Pg boundary (Labandeira et al. 2002) and severely unbalanced food webs in North America (Wilf et al. 2006). However, such alterations in the plant-insect interactions have not been observed in the Paleocene ecosystems of Europe (Wappler et al. 2009). It should be also noted that insect vectors appear to have a smaller relevance for viroid epidemiology than in the case of viruses (Van Bogaert et al. 2014). 


\section{Limitations of the method}

Molecuar dating in this study relies on the geographic provenance of viroids and their hosts. This is particularly important for the branch A that includes viroids infecting predominantly plants native to South America (Fig. 2). For example, the Potato spindle tuber viroid infects mainly Solanum tuberosum (potato), Solanum lycopersicum (tomato), and Capsicum annuum (pepper), which are all native to South America, whereas infections in other hosts are symptomless (Owens and Verhoeven 2009). However, the origin of viroids is often difficult to trace, which is caused by the human activity. For example, the Citrus exocortis viroid is well-known to infect citrus trees in Australia, which are native to Asia. However, it also infects tomato plants in Asia (Mishra et al. 1991), which are native to South America. The Citrus exocortis viroid is in fact closely related to several viroids typically infecting plants native to South America (Fig. 2).

Reliability of the method used in this study is partly dependent on the sample size. Since viroids constitute a small (or a poorly studied) group of pathogenic agents, nucleotide sequences of only 30 members of Pospiviroidae could be used to build the phylogenetic tree, whereas 4 members of Avsunviroidae were used for tree rooting (Table 1). The International Committee on Virus Taxonomy currently recognizes only 32 viroid species (Di Serio et al. 2017), which is even fewer than the 34 sequences studied herein. Notably, there are no divergence events recorded for the Santonian and Bartonian ages of the mid-Late Cretaceous and mid-Eocene epochs, respectively. This is possibly an effect of the poor sampling because the Santonian and the Bartonian are among the shortest ages of the interval studied (see Cohen et al. 2013, updated 2018). For this reason, more reliable results are obtained if the divergence rates are calculated for epochs (longer intervals) rather than for ages (Table 2; Fig. 3). On the other hand, the particularly long-lasting (8-million-years-long) lack of divergence events, which followed the $\mathrm{K}-\mathrm{Pg}$ mass extinction event, is here tentatively interpreted as a biotic event.

It should be noted that speciation rates inferred from extant species data are underestimated because the phylogenetic trees are obtained by suppressing all extinct lineages (Stadler 2011). For the same reason, the methodology applied herein cannot estimate the extinction rates. Nevertheless, this study shows that relative divergence rates of Pospiviroidae varied between geologic epochs. These differences may reflect paleoecologic changes and particularly events concerning the biodiversity of infected angiosperm plants or possibly interactions of plants with vectors (such as insects) transmitting plant viruses and viroids.

The lack of divergence events during the Neogene and the Quaternary on the constructed phylogenetic tree can be explained as an artifact caused by evolution on a subspecies level. Only nucleotide sequences arbitrarily classified as separate viroid "species" in literature and the NCBI database were included. The analyses have not involved different isolates of the same viroid. 


\section{Conclusions}

The evolution of Pospiviroidae might have been partly shaped by the evolutionary history of their hosts. It appears that a collapse of food chains (the lack of appropriate vectors transmitting pathogens) and a mass extinction of species (the paucity and isolation of infected hosts) may severely impact viral and subviral pathogens resulting in a decrease of their divergence rates. This hypothetically occurred during the K-Pg mass extinction but results obtained in this study are preliminary and require a thorough testing in future research. As viroids constitute a small group, the study of divergence rates of viruses would provide an important control. Intriguingly, given their abundance in most environments, viruses and subviral pathogens might potentially be useful in the study of the state of the biosphere.

\section{Acknowledgements}

I would like to thank two anonymous journal reviewers and the editor Prof. Frans Jorissen for thoughtful comments, which allowed to improve the quality of the work.

\section{Author contribution}

Piotr Bajdek conceived and designed the experiments, contributed analysis tools, performed the experiments, analyzed the data, prepared figures and tables, and wrote the manuscript.

Table 3.

\begin{tabular}{l|l|l}
\hline Authors & Contribution & $\mathrm{ACl}$ \\
\hline $\mathrm{PB}$ & 1.00 & $\mathrm{NA}$ \\
\hline
\end{tabular}

\section{References}

AbouHaidar MG, Venkataraman S, Golshani A, Liu B, Ahmad T (2014) Novel coding, translation, and gene expression of a replicating covalently closed circular RNA of $220 \mathrm{nt}$. PNAS 111 (40): 14542-14547. https://doi.org/10.1073/pnas.1402814111

Aswad A, Katzourakis A (2012) Paleovirology and virally derived immunity. Trends in Ecology and Evolution 27(11): 627-636. https://doi.org/10.1016/j.tree.2012.07.007

Card SD, Pearson MN, Clover GRG (2007) Plant pathogens transmitted by pollen. Australasian Plant Pathology 36: 455-461. https://doi.org/10.1071/AP07050

Cech TR (2012) The RNA Worlds in Context. Cold Springs Harbor Perspectives in Biology 4: a006742. https://doi.org/10.1101/cshperspect.a006742

Chela-Flores J (1994) Are viroids molecular fossils of the RNA world? Journal of Theoretical Biology 166: 163-166. https://doi.org/10.1006/jtbi.1994.1014 
Chin K, Pearson D, Ekdale AA (2013) Fossil Worm Burrows Reveal Very Early Terrestrial Animal Activity and Shed Light on Trophic Resources after the End-Cretaceous Mass Extinction. PLoS ONE 8(8): e70920. https://doi.org/10.1371/journal.pone.0070920

Cohen KM, Finney SC, Gibbard PL, Fan J-X (2013, updated 2018) The ICS International Chronostratigraphic Chart. Episodes 36(3): 199-204. https://dspace.library.uu.nl/handle/1874/289106

Daròs JA, Elena SF, Flores R (2006) Viroids: an Ariadne's thread into the RNA labyrinth. European Molecular Biology Organization Reports 7(6): 593-598. https://doi.org/10.1038/ sj.embor.7400706

Di Serio F, Li SF, Pallás V, Owens RA, Randles JW, Sano T, Verhoeven J, Vidalakis TTG, Flores R (2017) Viroid taxonomy. In: Hadidi A, Flores R, Randles J, Palukaitis P (Eds) Viroids and Satellites. Academic Press, pp 135-146. https://doi.org/10.1016/B978-0-12-801498-1.00013-9

Di Serio F, Li S, Matoušek J, Owens RA, Pallás V, Randles JW, Sano T, Verhoeven JTJ, Vidalakis G, Flores R, ICTV Report Consortium (2018) ICTV Virus Taxonomy Profile: Avsunviroidae. Journal of General Virology 99: 611-612. https://doi.org/10.1099/jgv.0.001045

Diener TO (1971) Potato spindle tuber "virus". IV. A replicating, low molecular weight RNA. Virology 45: 411-428. https://doi.org/10.1016/0042-6822(71)90342-4

Diener TO (2003) Discovering viroids - a personal perspective. Nature Reviews Microbiology 1: 75-80. https://doi.org/10.1038/nrmicro736

Elena SF, Dopazo J, Flores R, Diener TO, Moya A (1991) Phylogeny of viroids, viroidlike satellite RNAs, and the viroidlike domain of hepatitis \& virus RNA. Proceedings of the National Academy of Sciences 88: 5631-5634. https://doi.org/10.1073/pnas.88.13.5631

Elena SF, Dopazo J, de la Peńa M, Flores R, Diener TO, Moya A (2001) Phylogenetic Analysis of Viroid and Viroid-Like Satellite RNAs from Plants: A Reassessment. Journal of Molecular Evolution 53: 155-159. https://doi.org/10.1007/s002390010203

Feschotte C, Gilbert C (2012) Endogenous viruses: insights into viral evolution and impact on host biology. Nature Reviews Genetics 13: 283-296. https://doi.org/10.1038/nrg3199

Flores R, Hernández C, Martínez de Alba AE, Daròs J-A, Di Serio F (2005) Viroids and Viroid-Host Interactions. Annual Review of Phytopathology 43: 117-139. https://doi. org/10.1146/annurev.phyto.43.040204.140243

Flores R, Ruiz-Ruiz S, Serra P (2012) Viroids and Hepatitis Delta Virus. Seminars in Liver Disease 32(3): 201-210. https://doi.org/10.1055/s-0032-1323624

Flores R, Gago-Zachert S, Serra P, Sanjuán R, Elena SF (2014) Viroids: Survivors from the RNA World? Annual Review of Microbiology 68: 395-414. https://doi.org/10.1146/ annurev-micro-091313-103416

Fu Q, Bienvenido Diez J, Pole M, García Ávila M, Liu Z-J, Chu H, Hou Y, Yin P, Zhang G-Q, Du K, Wang X (2018) An unexpected noncarpellate epigynous flower from the Jurassic of China. eLife 7: e38827. https://doi.org/10.7554/eLife.38827

Gilbert W (1986) Origin of life: The RNA world. Nature 319: 618. https://doi. org/10.1038/319618a0

Góra-Sochacka A (2004) Viroids: unusual small pathogenic RNAs. Acta Biochimica Polonica 51(3): 587-607. https://pdfs.semanticscholar.org/6ceb/12e8550cc773781e1a03bedfcefda 9bb419c.pdf 
Gray SM, Banerjee N (1999) Mechanisms of Arthropod Transmission of Plant and Animal Viruses. Microbiology and Molecular Biology Reviews 63: 128-148. https://mmbr.asm. org/content/mmbr/63/1/128.full.pdf

Herendeen PS, Friis EM, Pedersen KR, Crane PR (2017) Palaeobotanical redux: revisiting the age of the angiosperms. Nature Plants 3: 17015. https://doi.org/10.1038/nplants.2017.15

Kumar S, Stecher G, Li M, Knyaz C, Tamura K (2018) MEGA X: Molecular Evolutionary Genetics Analysis across computing platforms. Molecular Biology and Evolution 35: 15471549. https://doi.org/10.1093/molbev/msy096

Labandeira CC, Johnson KR, Wilf P (2002) Impact of the terminal Cretaceous event on plantinsect associations. PNAS 99, 2061-2066. https://doi.org/10.1073/pnas.042492999

McElwain JC, Punyasena SW (2007) Mass extinction events and the plant fossil record. Trends in Ecology and Evolution 22(10): 548-57. https://doi.org/10.1016/j.tree.2007.09.003

Mello B (2018) Estimating TimeTrees with MEGA and the TimeTree Resource. Molecular Biology and Evolution 35(9): 2334-2342. https://doi.org/10.1093/molbev/msy133

Mishra MD, Hammond RW, Owens RA, Smith DR, Diener TO (1991) Indian bunchy top disease of tomato plants is caused by a distinct strain of citrus exocortis viroid. Journal of General Virology 72: 1781-1785. https://doi.org/10.1099/0022-1317-72-8-1781

Nei M, Kumar S (2000) Molecular Evolution and Phylogenetics. Oxford University Press, New York.

Niedźwiedzki G, Bajdek P, Qvarnström M, Sulej T, Sennikov AG, Golubev VK (2016) Reduction of vertebrate coprolite diversity associated with the end-Permian extinction event in Vyazniki region, European Russia. Palaeogeography, Palaeoclimatology, Palaeoecology 450: 77-90. https://doi.org/10.1016/j.palaeo.2016.02.057

Novacek MJ (1999) 100 Million Years of Land Vertebrate Evolution: The Cretaceous-Early Tertiary Transition. Annals of the Missouri Botanical Garden 86: 230-258. https://doi. org/10.2307/2666178

Owens RA, Verhoeven JTJ (2009) Potato spindle tuber. The Plant Health Instructor. https:// doi.org/10.1094/PHI-I-2009-0804-01

Owens RA, Flores R, Di Serio F, Li S-F, Pallás V, Randles JW, Sano T, Vidalakis G (2012) Viroids. In: King AMQ, Adams MJ, Carstens EB, Leftkowitc EJ (Eds) Ninth Report of the International Committee on Taxonomy of Viruses, 1221-1234.

Patel MR, Emerman M, Malik HS (2011) Paleovirology - Ghosts and gifts of viruses past. Current Opinion in Virology 1(4): 304-309. https://doi.org/10.1016/j.coviro.2011.06.007

Rao ALN, Kalantidis K (2015) Virus-associated small satellite RNAs and viroids display similarities in their replication strategies. Virology 479-480: 627-636. https://doi.org/10.1016/j. virol.2015.02.018

Raup DM, Sepkoski Jr JJ (1982) Mass Extinctions in the Marine Fossil Record. Science 215: 1501-1503. https://doi.org/10.1126/science.215.4539.1501

Seton M, Müller RD, Zahirovic S, Gaina C, Torsvik T, Shephard G, Talsma A, Gurnis M, Turner M, Maus S, Chandler M (2012) Global continental and ocean basin reconstructions since 200 Ma. Earth-Science Reviews 113: 212-270. https://doi.org/10.1016/j.earscirev.2012.03.002

Shukla A, Mehrotra RC, Guleria JS (2012) Cocos sahnii Kaul: A Cocos nucifera L.-like fruit from the Early Eocene rainforest of Rajasthan, western India. Journal of Biosciences 37: 769-776. https://doi.org/10.1007/s12038-012-9233-3 
Stadler T (2011) Inferring speciation and extinction processes from extant species data. PNAS 39: 16145-16146. https://doi.org/10.1073/pnas.1113242108

Suh A, Brosius J, Schmitz J, Kriegs JO (2013) The genome of a Mesozoic paleovirus reveals the evolution of hepatitis B viruses. Nature Communications 4: 1791.https://doi.org/10.1038/ ncomms 2798

Suh A, Weber CC, Kehlmaier C, Braun EL, Green RE, Fritz U, Ray DA, Ellegren H (2014) Early Mesozoic Coexistence of Amniotes and Hepadnaviridae. PLOS Genetics 10(12): e1004559. https://doi.org/10.1371/journal.pgen.1004559

Sun G, Ji Q, Dilcher DL, Zheng S, Nixon KC, Wang X (2002) Archaefructaceae, a New Basal Angiosperm Family. Science 296: 899-904. https://doi.org/10.1126/science.1069439

Syller J, Marczewski W, Pawłowicz J (1997) Transmission by aphids of potato spindle tuber viroid encapsidated by potato leafroll luteovirus particles. European Journal of Plant Pathology 103: 285-289. https://doi.org/10.1023/A:1008648822190

Taylor DJ, Ballinger MJ, Zhan JJ, Hanzly LE, Bruenn JA (2014) Evidence that ebolaviruses and cuevaviruses have been diverging from marburgviruses since the Miocene. PeerJ 2: e556. https://doi.org/10.7717/peerj.556

Thézé J, Bézier A, Periquet G, Drezen JM, Herniou EA (2011) Paleozoic origin of insect large dsDNA viruses. PNAS 38: 15931-15935. https://doi.org/10.1073/pnas.1105580108

Tsagris EM, Martínez de Alba ÁE, Gozmanova M, Kalantidis K (2008) Viroids. Cellular Microbiology 10(11): 2168-2179. https://doi.org/10.1111/j.1462-5822.2008.01231.x

Van Bogaert N, Smagghe G, De Jonghe K (2014) Viroid-insect-plant interactions. In: Gaur RK, Hohn T, Sharma P (Eds) Plant Virus-Host Interaction. Academic Press, 277-290. https://doi.org/10.1016/B978-0-12-411584-2.00015-9

Verhoeven JThJ, Meekes ETM, Roenhorst JW, Flores R, Serra P (2013) Dahlia latent viroid: a recombinant new species of the family Pospiviroidae posing intriguing questions about its origin and classification. Journal of General Virology 94: 711-719. https://doi. org/10.1099/vir.0.048751-0

Verhoeven JTJ, Flores R, Serra P (2017) Iresine Viroid 1 and a Potential New Pospiviroid From Portulaca. In: Hadidi A, Flores R, Randles JW, Palukaitis P (Eds) Viroids and Satellites. Academic Press, 191-198. https://doi.org/10.1016/B978-0-12-801498-1.00018-8

Wang X (2017) A Biased, Misleading Review on Early Angiosperms. Natural Science 9(12): 399-405. https://doi.org/10.4236/ns.2017.912037

Wang L-F, Walker PJ, Poon LLM (2011) Mass extinctions, biodiversity and mitochondrial function: are bats 'special' as reservoirs for emerging viruses? Current Opinion in Virology 1: 649-657. https://doi.org/10.1016/j.coviro.2011.10.013

Wappler T, Currano, ED, Wilf P, Rust J, Labandeira CC (2009) No post-Cretaceous ecosystem depression in European forests? Rich insect-feeding damage on diverse middle Palaeocene plants, Menat, France. Proceeding of the Royal Society B 276: 4271-4277. https://doi. org/10.1098/rspb.2009.1255

Wilf P, Johnson KR (2004) Land plant extinction at the end of the Cretaceous: a quantitative analysis of the North Dakota megafloral record. Paleobiology 30: 347-368. https://doi. org/10.1666/0094-8373(2004)030<0347:LPEATE>2.0.CO;2

Wilf P, Labandeira CC, Johnson KR, Ellis B (2006) Decoupled Plant and Insect Diversity After the End-Cretaceous Extinction. Science 313: 1112-1115. https://doi.org/10.1126/science.1129569 